\title{
DESCRIPTION OF A TRAVELLING CRANE WORKED BY CLIP DRUM AND WIRE ROPE.
}

By Mr. JOHN FERNIE, OF LeEds.

Few mechanical improvements have been so rapidly and so extensively adopted as the quick-rope Travelling Crane, introduced by Mr. Ramsbottom at the Crewe Works, a description of which was given by him to this Institution in 1864. During the short interval that has since elapsed, the extension of the application of this system has been so great, that at the present time there is scarcely a shop for the manufacture or repair of locomotive engines but has several of these cranes at work.

The Travelling Crane forming the subject of the present paper has been invented at the Steam Plough Works, Leeds, where there has been great experience in the manufacture and working of steel wire ropes; and the idea occurred that an improvement could be made by adopting a steel wire rope working with a clip drum, instead of a cotton rope acting by friction only; and that for out-door work, in quarries or over docks for shipbuilding, where a cotton rope would be subject to injury by exposure to the weather, a steel wire rope would be preferable. A case has indeed recently arisen where it would be impossible to make use of a cotton cord, the crane being employed in a large armour-plate mill for carrying away the plates on leaving the rolls; and the heat from such large masses of iron is so great that a cotton cord as usually applied would be quickly burnt up. For the same reason it has been found necessary in this instance that the man working the crane should be kept at a distance from the heat, and he is therefore stationed in a box at one end of the travelling frame, instead of being placed immediately over the work as usual. 
The application of a steel wire rope and clip drum for communicating power formed the subject of a previous paper read before this Institution by the late Mr. John Fowler and Mr. David Greig on the application of steam power to the cultivation of the soil (see Proceedings Inst. M.E. 1865 page 55); and the crane now to be described is only a further adaptation of the same means for communicating power at varying distances from the prime mover.

This Crane is employed at the Steam Plough Works, Leeds, for lifting locomotive engines and other heavy work ranging from 15 tons downwards; it has a span of 40 feet, and traverses a length of 180 feet. The three different motions, for longitudinal traverse, cross traverse, and hoisting, are all derived from one endless steel wire rope, $\frac{3}{4}$ inch diameter, and weighing $2 \mathrm{lbs}$. per yard. This rope is driven at a speed of 4 miles an hour by means of a clip pulley fixed at one end of the shop, which is driven by belts and gearing from the engine working the shop. The rope extends the whole length of one side of the shop, going and returning on the same side at the level of the traveller, and passing round a loose pulley at the further end of the shop. The rope is entirely unsupported between the two ends of the shop, and is not strained tight, but hangs loose with only a slight tension, because the peculiar action of the clip pulley allows of the whole power being communicated to the rope by the grip of the pulley through half its circumference, even when the tail rope is entirely slack.

The construction of the crane is shown in Figs. 1 to 11, Plates 82 to 87. The clip pulley A, Fig. 1, fixed at the end of the shop, is speeded to drive the wire rope $\mathbf{B} B$ at the rate of 4 miles per hour, and lays hold of the rope with an amount of grip proportionate to the strain thrown upon the rope by the load, releasing it from its grasp when the rope has passed the centre line. The construction and fixing of the moveable jaws or clips round the circumference of the clip pulley is shown one third full size in Figs. 10 and 11, Plate 87. At one end of the travelling platform $\mathrm{C}$ of the crane is fixed another clip pulley D, Figs. 3 and 4, of the same size and construction, round which the same wire rope passes, making three quarters of a turn 
round it. The rope then passes on to the further end of the shop, and round the grooved pulley $\mathrm{E}$ at that end, Figs. 1 and 3 ; this pulley is centred in a sliding frame provided with an adjusting screw $G$, for tightening up the rope to any tension required. It has not been found necessary to have any sliding weight attached to this frame, for variable tension of the rope; nor indeed has the original adjustment been altered since the crane was first put to work about two years ago. The wire rope has no slippers or carrying pulleys to support it, and is consequently free from the friction that accompanies their use; nor is it proposed to put any carrying pulleys for distances under 600 feet. The shop in which the present crane works is 180 feet long, and the rope hangs in a catenary curve through that distance, the deflection from a straight line being from 3 inches to 2 feet, according to the degree of tightening by the end pulley $\mathrm{E}$.

The gearing for working the longitudinal traverse and the cross traverse is of the ordinary description, the motion being communicated from the clip pulley $D$ on the traveller by means of friction clutches. The longitudinal traverse has a speed of 30 feet per minute, and the cross traverse 20 feet per minute.

The lifting gear consists of a very long cast-iron nut or screwed barrel $\mathrm{HH}$, extending nearly the whole length of the traveller, as shown in the plan, Fig. 2, and to a larger seale in Figs. 5 and 6 , Plate 85 ; and inside the barrel works a short screw I, Fig. 5, sliding on two feathers upon the long shaft $J J$, which is driven by a friction clutch from the clip pulley $D$ on the traveller, so that by the revolution of the shaft the screw is traversed along within the barrel. The long driving shaft $J$ is supported at intermediate points of its length by the two sliding brass steps $\mathrm{KK}$, Figs. 5 and 7 , sliding along freely within the barrel $\mathrm{H}$, and kept apart from each other at the distance of half the length of the barrel by the long rod $L$; by this means the shaft $J$ is never left unsupported for more than half of its length. The screwed barrel $H$ is cast in two halves longitudinally, and bolted together, as shown in Fig. 6 ; and the pitch of the screw thread is $1 \frac{3}{4}$ inch, the diameter being $6 \frac{1}{2}$ inches. 
One end of the hoisting chain being attached to the screw frame $\mathrm{M}$, Fig. 5, the chain $\mathrm{N}$ passes along through the inside of the barrel $\mathrm{H}$, round a pulley $P$, Fig. 2, at the further end of the traveller; then over a pulley on the cross-traversing carriage R, Figs. 8 and 9, down to the snatch-block $S$, and up again over a second pulley on the carriage $R$; and the end is attached to the nearer extremity of the traveller at $\mathrm{T}$, Fig. 2. There is no reason however why an ordinary crab might not be used, worked by a shaft extending from end to end of the traveller; and that plan is adopted in a second crane now being erected at the Steam Plough Works, and also in the crane for the armour-plate mill previously referred to; but for heavy weights it is still considered that the long screwed barrel above described is preferable. The crane has two speeds for the lifting gear, one being at the rate of 6 feet per minute, and the other at the rate of 3 feet per minute; and at the latter speed the crane is calculated to lift 15 tons.

It is most desirable that all machinery of this kind should be kept constantly running, so as to be available for immediate use at any moment when required, without any delay for starting it to work; but inasmuch as the total time during which the crane is actually in use does not amount to more than about one hour out of ten, it is of special importance that the power employed to drive the rope when the crane is not in use should be reduced to as small an amount as possible. If a quick-running rope is employed, the absorption of power for keeping it in constant motion forms a large proportion of the total power required when lifting a load, and this is a loss which is always going on throughout the day; but when a slow speed of rope is employed, this constant loss is greatly reduced. The pull required to put the wire rope in motion when the crane is standing idle is $128 \mathrm{lbs}$. When lifting a load of 10 tons at the usual speed of 3 feet per minute, the additional pull upon the rope due to the load is 191 lbs., making the total pull 319 lbs.; and the horse power required with the wire rope is consequently 3.4 horse power with a load of 10 tons, and only 1.4 horse power when standing idle, these amounts being very much less than in the case of the quickmoving cord crane. 
This crane has been in use at the Steam Plough Works for two years, and has been found to be easily and cheaply worked; and not the least of its recommendations is that it is almost noiseless. The original wire rope is still working, and appears at the present time practically as good as the day it was started.

Mr. W. Clay observed that in the use of cranes driven by a quickrunning cotton cord he had found it impossible during the recent cotton famine to get cotton cords that would stand for any considerable length of time, as the only cord that could then be obtained for the purpose was made of common Surat cotton, which was not good enough to stand the work. Under these circumstances he had got over the difficulty by using a hide rope, which was found to last for about eighteen months without any serious wear and tear. Although therefore the wire rope now described might be a great improvement over the ordinary cotton cord, still as there were already so many cranes at work driven by the quick-running cotton cord, it might be useful to know that a hide rope could be employed for the same cranes, and would last longer than the cotton cord.

Mr. E. A. Cowper enquired whether any trial had been made of running a light steel wire rope at the same speed as the cotton cord, and so using it to work one of the cranes hitherto driven by the cotton cord. In the crane now described he thought the lifting speeds of 3 and 6 feet per minute seemed rather slow in comparison with the longitudinal and cross traversing motions of 30 and 20 feet per minute; and the latter were perhaps rather faster than usual in such cases.

Mr. Ferate believed that in engineering shops generally the speed of 6 feet per minute for hoisting light loads would be considered amply sufficient; and for heavy work 2 feet or even 
$1 \frac{1}{2}$ feet per minute was enough, and in the 25 ton traversing crane at the Crewe Works the lowest speed of lifting was not more than $\mathbf{1} \frac{1}{2}$ feet per minute. With regard to the use of a light steel wire rope in place of the present cotton cord, he did not think it would be possible to run even the lightest wire rope at anything like the speed of 40 or 60 miles an hour at which the cotton cord was driven, because the much greater weight of the steel rope would tell so seriously at a high speed, and the frequent bends would greatly reduce its durability; the important advantage in the cotton cord, which allowed of its being run at such a high speed, was its lightness.

Mr. D. Greig said they had now had considerable experience at the Steam Plough Works in driving cranes with both cotton and wire ropes. They had used one of the light rope cranes for four years, and had found it of great advantage as compared with previous modes of working cranes; but the cost of working and the power required to keep the cord constantly running at the high speed were so great, as well as the wear and tear, that they had been led to look for some other mode of driving, as that plan of crane was found so useful that they wished to retain it. The experience gained in the successful use of steel wire ropes for steam ploughing machinery suggested the adaptation of the same mode of driving for the crane; and the result had been that the crane described in the paper had now been in regular work for two years, during which time it had not cost $25 \mathrm{~s}$. for keeping it in repair. With the light cotton ropes running at a very high speed he understood it was the general experience that they were found difficult to keep in repair; and the slow moving rope was not only less expensive in this respect, but also had the advantage of giving the same power for lifting without costing nearly so much for the power for driving the rope continuously at a very high speed during all the time that the crane was standing idle. As the crane was required to be always ready for work at a moment's notice, without the delay of having to send men aloft to work the crabs of a hand crane, it was necessary for the rope to be kept constantly running; nor was it practicable to economise the power in the case of the quick-running rope, by 
stopping it at the times when the crane was not in use, becanse in starting it again the length of time required for getting up the high speed was as much as five minutes. Considerable difficulties had been met with at first in adapting the wire rope and clip drum to work the cranes; but these had now been successfully overcome, and in the course of a few months there would be several more of the wire-rope cranes at work in other engineering shops. At his own works the use of the wire-rope crane in the erecting shop bad been attended with a very great saving in the expense of lifting all descriptions of work in the shop. To work the cranes by a light steel rope driven at the same speed as the cotton cord would be quite impracticable, on account of the weight of the steel rope and the number of bends it would have to make round pulleys of small diameter. The speed at which the wire rope was driven had nothing to do with the speed of lifting, the latter being previously determined by the proportions of the gearing, so as to give two speeds for lifting, 3 feet and 6 feet per minute, with a constant speed of 4 miles an hour for the rope; and the only effect of changing from the lower to the higher speed in lifting was to double the strain on the rope, without requiring the speed of the rope to be altered.

Mr. E. A. Cowper enquired what was the actual strain upon the wire rope at the two speeds of lifting.

Mr. D. Greig replied that in lifting loads of 10 tons and 15 tons at the usual speed of 3 feet per minute the strain upon the rope was from 3 to $4 \mathrm{cwts.}$; and even if the same loads were lifted at the higher speed of 6 feet per minute, the strain on the rope would not exceed $4 \frac{1}{2}$ to $6 \frac{1}{2} \mathrm{cwts.}$ A rope of that size however, $\frac{3}{4}$ inch diameter, would safely bear a pull of $15 \mathrm{cwts}$. in steam ploughing machinery. The main object in using the wire rope for working the crane was to run the rope as slow as possible, requiring of course a corresponding increase of strain apon the rope; and the limit to the strain that cuuld be put upon the rope would be the amount of adhesion of the carrying wheels of the traveller upon the rails, so that the crane should not only be able to stand stationary against the pull of the rope, but should also be capable of travelling in the opposite direction to the pull. 
Mr. C. W. Siemens mentioned that at the Paris Exhibition in the previous year a plan had been shown of transmitting power to a great distance by means of a steel wire rope driven at a very high speed and running over large pulleys; and this plan had been employed in the mountainous districts of France and Switzerland for transmitting the power from a water wheel or turbine to a distance of half a mile or more up a mountain. There was less wear in this case he understood than was usually experienced in the working of wire ropes, probably owing to the circumstance that the distance travelled by the rope without any bends was so great, the bends being perhaps not more than one at each end of the entire distance. The rope was not driven by a clip drum, but by pulleys of $6 \frac{1}{2}$ feet diameter; and the intermediate carrying pulleys were also of large diameter. The speed of the rope was very great, but the strain upon it was small because of the speed; and he had been informed it was found to perform the work exceedingly well, transmitting a large amount of power.

Mr. E. A. CowPER thought in the case referred to there must be a considerable amount of sag in the rope between the carrying pulleys, as there was not a heavy pull upon it to keep it up.

Mr. H. Chapman mentioned that the quick-running wire rope shown at work at the Paris Exhibition on Hirn's plan had broken shortly before the Exhibition closed; it had been at work about seven months, driving a centrifugal pump of about 25 horse power at a distance of 500 feet, the rope being rather less than $\frac{1}{3}$ inch diameter.

Mr. Fernie observed that in the crane now described, driven by a wire rope running at a slow speed, the main feature was the application of the clip pulley for driving the rope; and the important practical advantage attending the clip drum was that it did away with the sawing action of the rope in the ordinary $\mathbf{V}$ groove of a pulley, the clips laying hold of the rope with an amount of grip proportionate to the pull upon the rope, and holding it absolutely fast at the moment, and afterwards completely releasing it from their grasp as soon as it arrived at the point where it was a tangent to the pulley. By this means any power that was desired 
could be transmitted by the clip pulley, without involving either the loss from friction or the wear and tear of rope attending the use of the ordinary grooved pulleys. Another advantage of the new plan was the low speed at which the wire rope had to be driven, in consequence of which the power required for driving it was only $1 \frac{1}{2}$ horse power when the crane was standing idle, and $3 \frac{1}{2}$ horse power in lifting a load of 10 tons at 3 feet per minute, the rope running at a speed of only 4 miles an hour. From experiments made with the previous crane at the Steam Plough Works, driven by the cotton cord running at 40 miles an hour, he had found that the power expended in driving the cord while the crane was standing amounted to as much as 12 horse power, and to 14 horse power when lifting a load of 10 tons at 3 feet per minute. This amount of driving power seemed so disproportionately great as to lead to the supposition that the crane must have been of defective construction in some respects; but even supposing that were the case, he was satisfied the quick-running cord absorbed under favourable circumstances at least four times as much driving power as the slow wire rope. As a workshop crane was required to be always ready for use, it was important that it should be kept in readiness with the smallest constant expenditure of power during the time it was standing idle; and this was satisfactorily accomplished in the wire-rope crane, by keeping the rope always going at the slow speed.

Mr. D. GREIG said he had kept an account of the time during which the crane was in actual ase, and had found it did not average more than one hour in each day, as so much time was consumed in the intervals between lifting, traversing, lowering, and fixing the work moved by the crane; but the rope had to be kept going continuously during the whole time, in order that the power might be ready for instant use whenever required.

Mr. B. WALKER said he had one of the quick-rumning cranes in use at his own works and had also made several of them, and he did not think the power required for driving the cotton cord was so great as had been mentioned; he considered there must have been something defective causing extra friction in the crane which was found to absorb so large an amount of driving power, as the pull upon the 
cord required for lifting the load alone was only about $1 \mathrm{lb}$. per ton of load when the cord was run at 60 miles per hour. He had also made one of the wire-rope cranes for Woolwich arsenal, in which the rope was driven at 6 miles an hour under a constant pull of $10 \mathrm{cwts.}$; and although it was certainly found to take less power for driving than the quick crane, he did not think the difference was so much as one in four, and he doubted whether the quick cord took more than twice as much power as the slow wire rope. As regarded the durability of the cord, there was no doubt that the quick crane was troublesome, notwithstanding that the wear and tear had been considerably reduced by taking care to diminish the friction as far as possible, by employing well-made pulleys and having as fow bends as possible in the cord. But at the Crewe Works he understood one of the cotton cords had now been at work for seven months and was still in use; and the quick-running cranes employed there had been found so satisfactory that it had not been considered desirable to change to any other plan. $\mathrm{He}$ thought however, if the wire rope was found to be durable, that the slow-going wire-rope crane would become more general, because it did not require such good workmanship as was necessary in the high-speed crane.

Mr. C. E. Amos remarked that he had seen the working of the wire-rope crane at the Steam Plough Works and could fully endorse what had been stated as to its advantages; it appeared practically a very useful machine, and he thought the principle of using the wire rope running at a slow speed was the correct one. He was certainly surprised at the very great amount of power required in the quick crane to drive the cotton cord at 40 miles an hour, and thought there must be some undue friction in that case, as the crane should not take anything like so much power for merely overcoming the friction. As to the durability of the cotton cord, if it did not last much more than seven months, he thought that would be a serious objection to the quick-running crane; and in many engineering shops he considered it might then be even better to return to hand cranes, than to be liable to a breakage of the driving cord occurring perhaps at a time when the crane might happen to be most wanted for a press of work. 
Mr. F. J. BRamwell observed that, although the power necessary for driving the quick-running cord appeared at first sight excessive, it must be borne in mind that, with the very high speed which was employed, a very small increase in the constant pull upon the cord soon mounted up to a large power; for at a speed of 40 miles an hour the pull upon the cord corresponding to a power of 1 horse power was no more than about $10 \mathrm{lbs}$. If therefore the pulleys of the crane were at all out of order, the small extra friction thereby occasioned would be sufficient at that high speed to account for a considerable increase in the driving power.

Mr. E. H. CARBUT thought the old plan of driving the crane by means of a shaft of square section running the whole length of the shop was preferable to the quick cord, because the power required to keep the shaft in motion while the crane was standing was altogether insignificant. A crane on that plan had been in use at his works for ten years, without any breakage of the driving shaft, and without any expense for repairs beyond ordinary wear and tear.

Mr. E. ReYrouns suggested that one important source of friction in the quick-running cranes might be the worm and wormwheel employed for working the crab, the rubbing surfaces being made at such an inclination that the load upon the crab would stand in any. position without running down, though no friction break was used; and he remembered it had been mentioned in the former description of the cranes at the Crewe Works, in which a wormwheel was employed, that a load on the crab, which would be equal to only 6 lbs. pull at the circumference of the driving pulley, was found to require as much as $17 \mathrm{lbs}$. to start it in lifting, showing that $11 \mathrm{lbs}$. or nearly double the theoretical power was absorbed in merely overcoming the friction of the worm when standing. Although arrangements of this class were sometimes very convenient, it should be remembered that any machine in which the friction was sufficient to sustain the load, and to check it if descending; must lose or consume in friction at least one half the power employed in hoisting.

Mr. B. WALKer said that, with regard to the loss of power occasioned by the friction of the worms in the quick-running cranes, they had made several of the cranes lately without the worms, the 
chain barrel of the crab being driven by spur gearing instead of the wormwheel; and in those cases the power required for working the crane was found to be considerably less than with the worms.

The Chairman considered the important feature in the wire-rope crane now described was undoubtedly the clip pulley, by which the application of the wire rope driven at so slow a speed had been rendered practicable; and it was this beautiful invention which had led to such successful results in the employment of wire ropes for the purposes of steam ploughing and cultivation. In the quick-running crane he thought there must certainly have been something wrong to require so great an amount of power as had been mentioned for working the crane; but he considered there conld be no question as to the saving of power that would be effected in the present plan with the use of the clip pulley, by running the driving rope at a slow speed.

He proposed a vote of thanks to Mr. Fernie for his paper, which was passed.

The following paper was then read:- 
WIRE-ROPE TRAVELLING CRANE.

Plate 82.

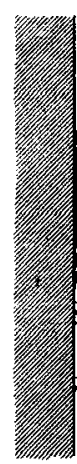

Fig. 1. Transwerse Section of Traveller.

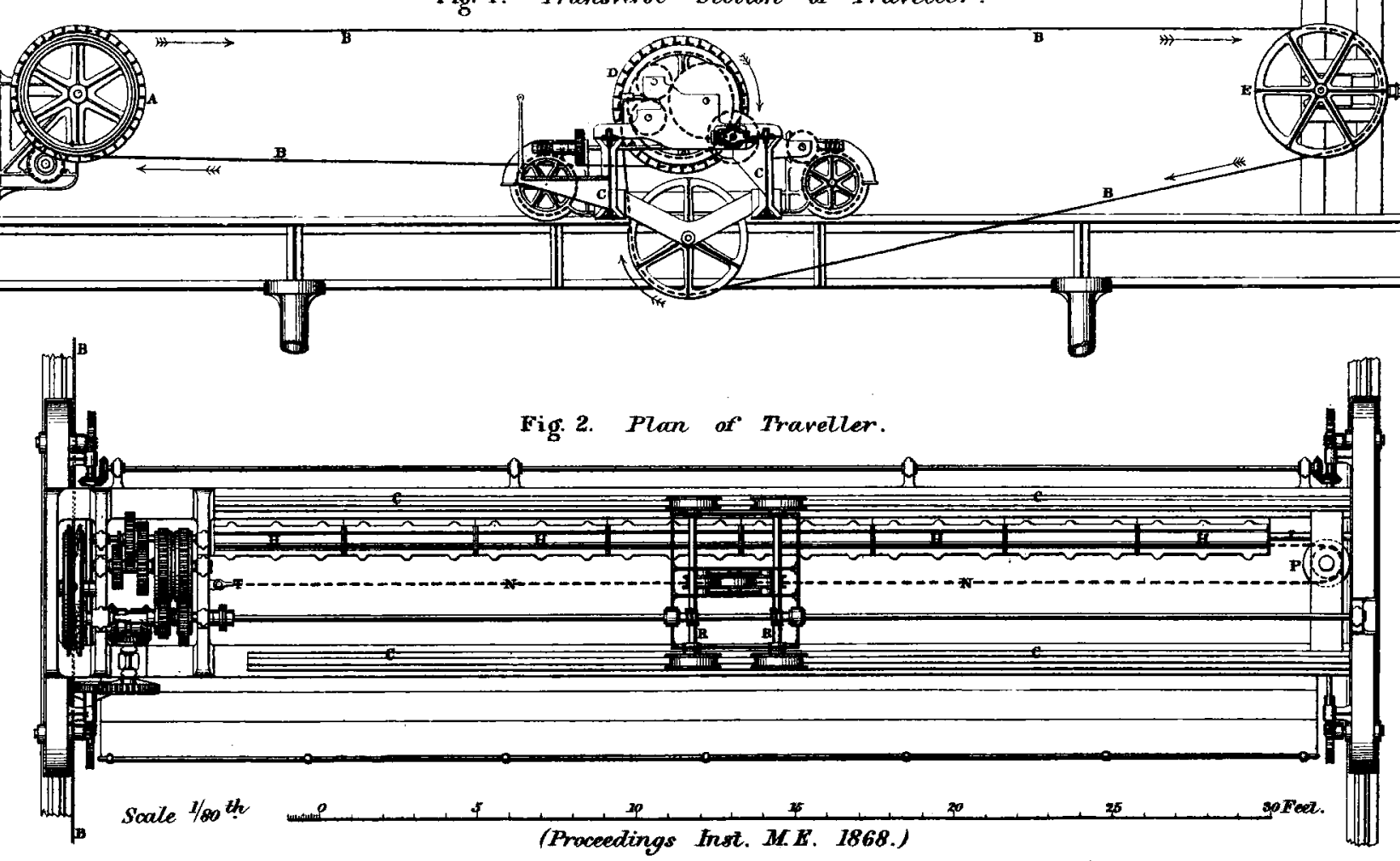


WIRE-ROPE TRAVELLING CRANE.

Fig. 3. Transverse Section of Traveller, enlarged.

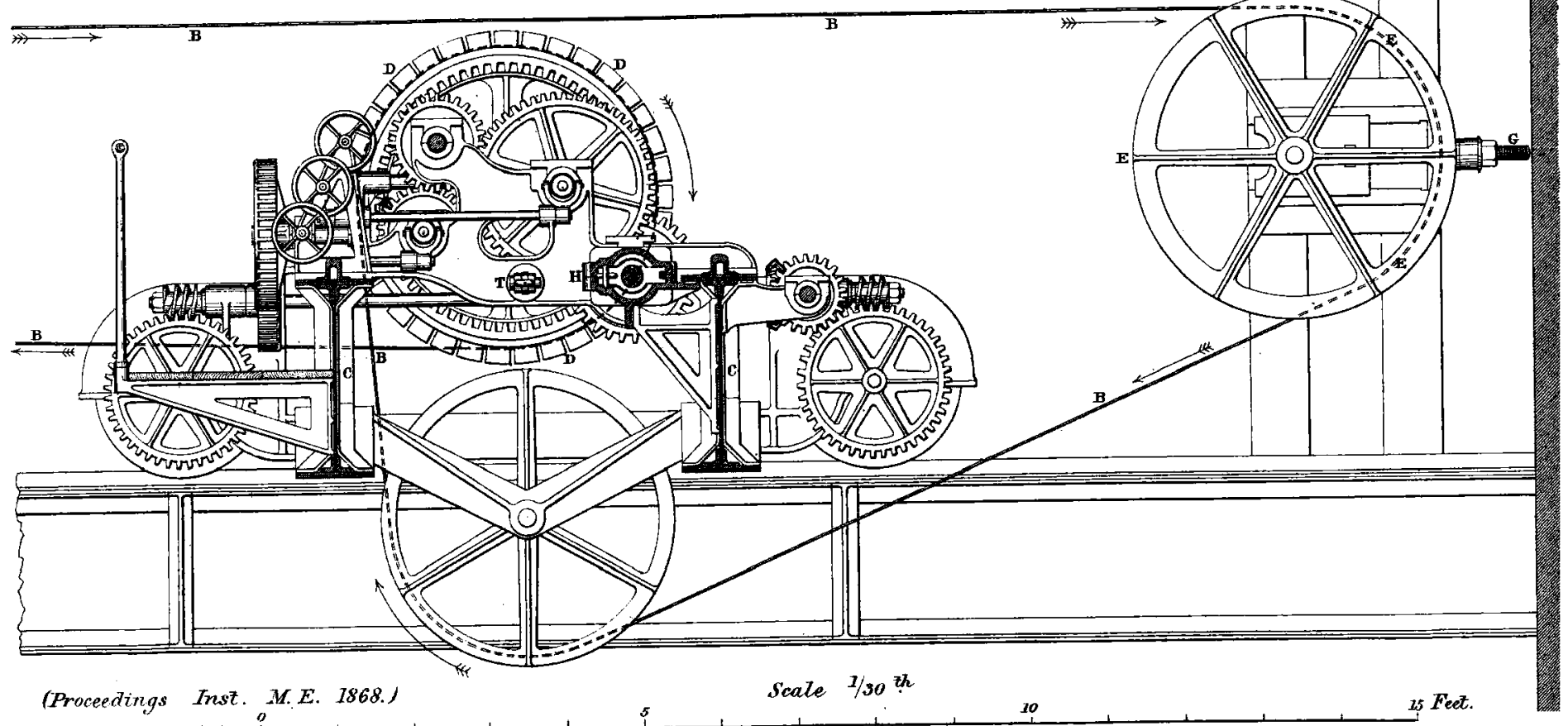


WIRE-ROPE TRAVELLING CRANE.

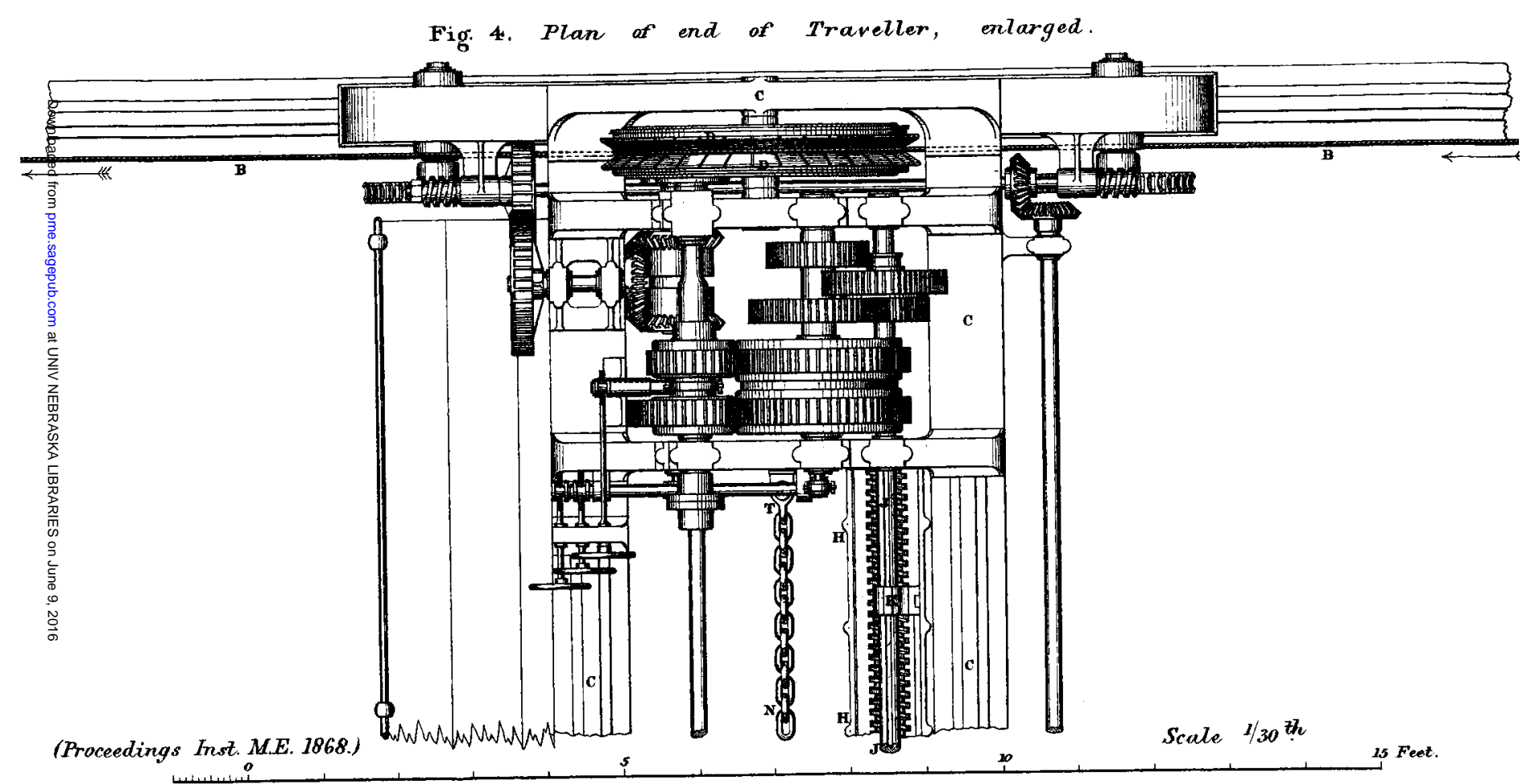


WIRE-ROPE TRAVELLING CRANE.

Fig. 5. Plan of Hoisting Screw and Screwed Barrel.

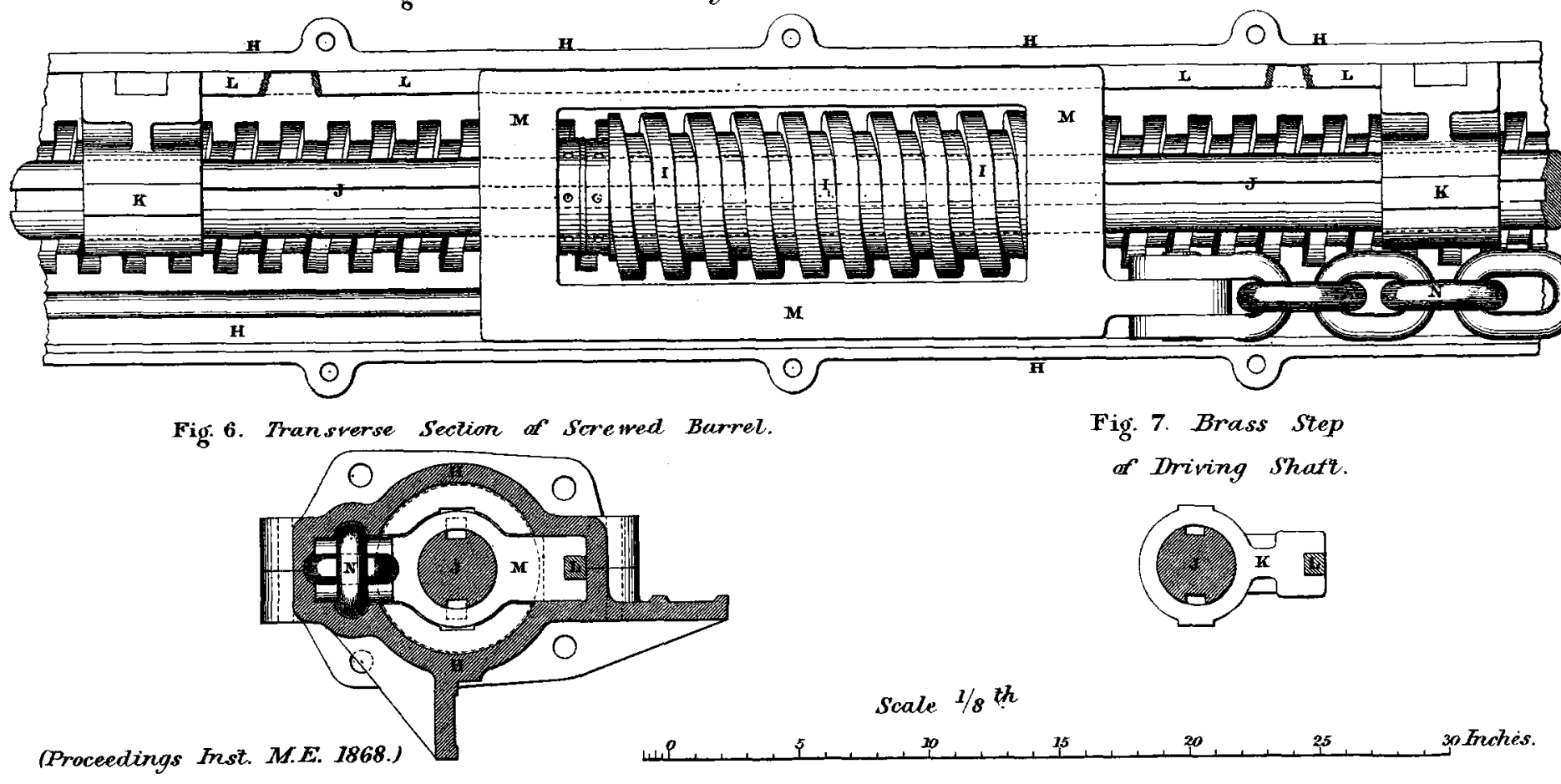


WIRE-ROPE TRAVELling CRANE. Plate 86.

Fig. 8. Elevazion of Cross Traversing carriage on Traveller.

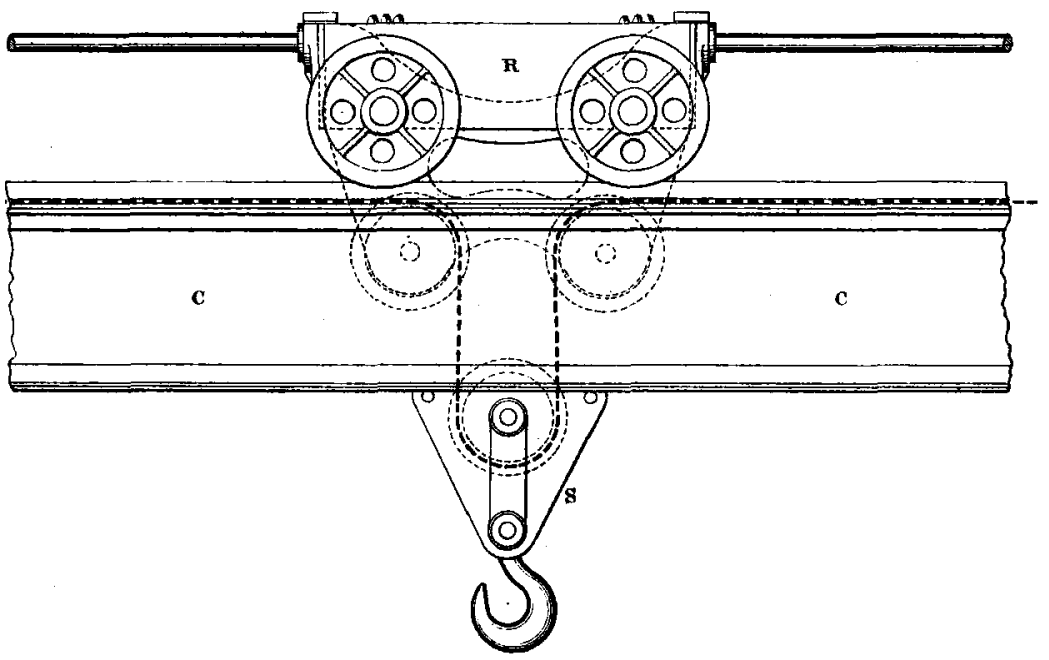

Fig. 9. Plan of Cross Traversing Carriage:

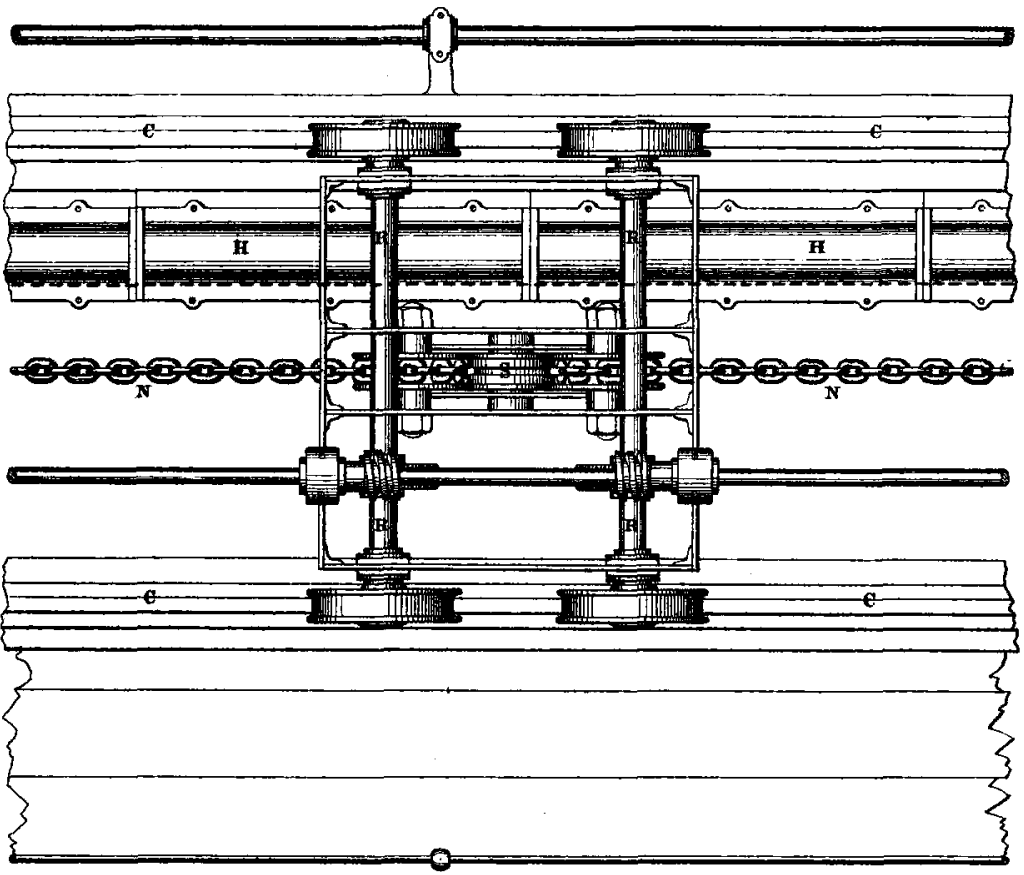

(Proceedings Inst. M.E. 1868.) Scate 1/30th

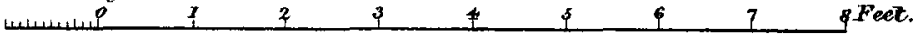


WIRE-ROPE TRAVELLING CRANE. Plate 87.

Fig. 10. Section of him of Clip Prelley.
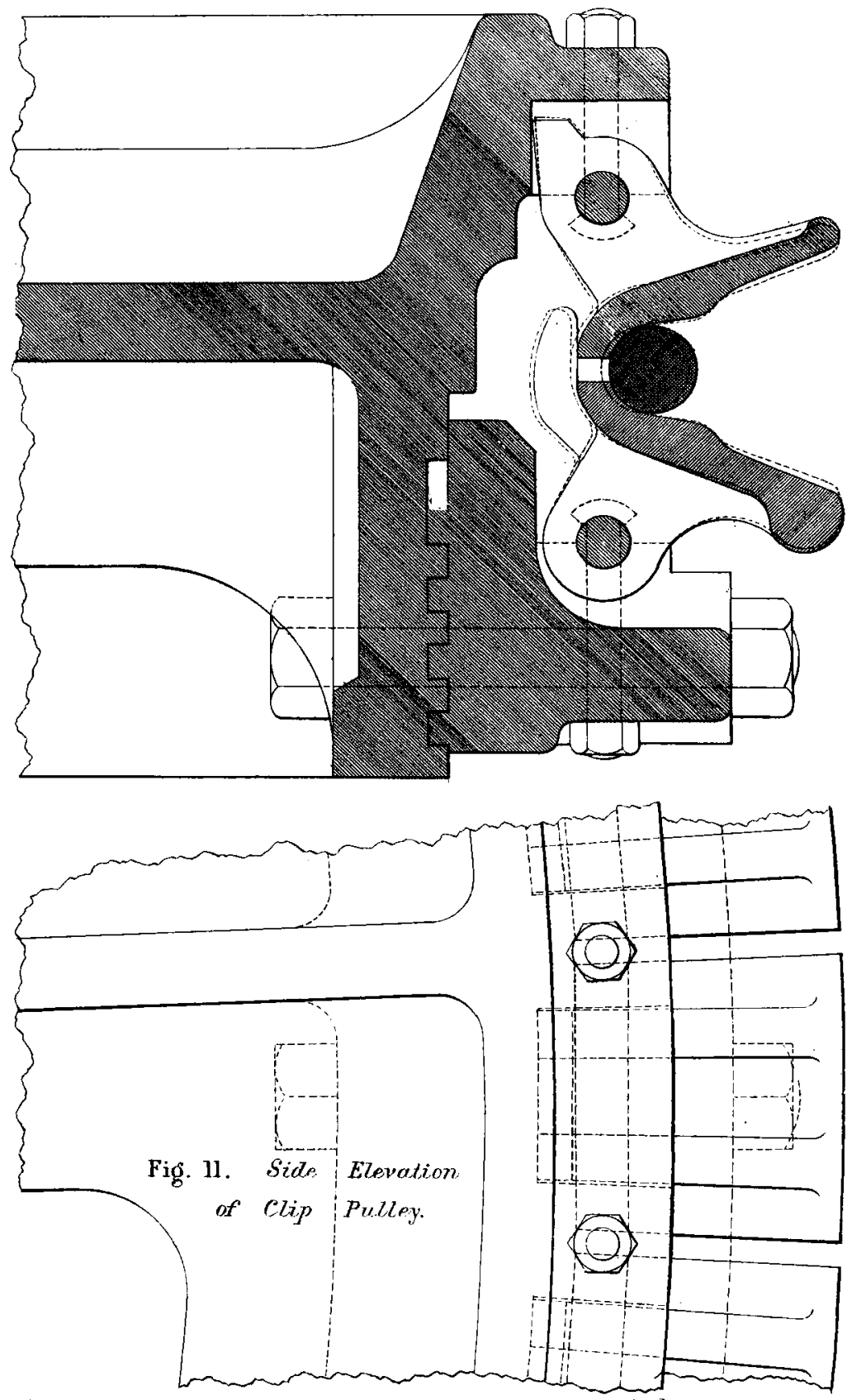

(Proceedtings.

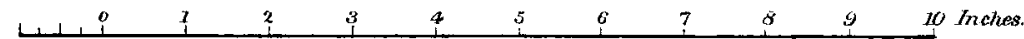

